\title{
Quantification Study of Non -Biodegradable Solid Waste Materials Accumulated in The Mangroves of Mahim Creek, Mumbai
}

\author{
Pravin U. Singare \\ Department of Chemistry, Bhavan's College, Munshi Nagar, Andheri (West), Mumbai, 400058, India
}

\begin{abstract}
In the present investigation quantification study on three major Non-Biodegradable Solid Waste (NBDSW) materials viz. plastics, synthetic rubber and glass was performed in the mangroves of Mahim creek of Mumbai. The study was performed before and after spring tide for the period of five months i.e. from October 2010 to February 2011. It was observed that plastics were the major dominating NBDSW materials contributing to $71 \%$ and $55 \%$, while contribution of synthetic rubber was found to be $26 \%$ and $41 \%$ during first and second sampling respectively. Also it was observed that contribution of synthetic rubber and glass materials was more after the spring tide as compared to that of before. These solid waste pollutants from various sources are affecting the mangrove ecosystem. Although most of these NBDSW materials can be controlled by recycling and incineration, the issue pertaining solid waste pollutants along the Mahim Creek seems to be completely neglected. The results of present study point out the need to make serious changes in our approach to waste management and disposal.
\end{abstract}

Keywords Solid Waste, NBDSW, Quantification, Synthetic Rubber, Plastics, Mahim Creek, Mumbai, India

\section{Introduction}

The cities of almost all South Asian countries are challenged by urbanization and industrialization trends, population increase and consequent rise in solid waste. Solid waste generation differs from place to place to a great extent; its production and composition are influenced by consumption pattern, climate, season, cultural practice, etc[1]. As for the case of Thimpu (Bhutan), it generates about 10 tons/day[2] and Dhaka (Bangladesh) generates as high as 4,364 tons of waste daily[3]. Average daily solid waste generation in Kabul city (Afganistan) is 1,080 tons out of which only 250 ton is collected[4]. In New Delhi (India) 3,880 tons of solid waste is generated each day of which only 2,420 tons is collected for disposal[5]. In Karachi (Pakistan), everyday around 7,000 tons of mixed garbage is generated and its generation rate is increasing by $2.4 \%$ per year[6]. In Kathmandu Metropolitan City (KMC), Nepal, daily garbage flow is $944 \mathrm{~m} 3$, approximately 300 tons[7] whereas; in Colombo (Sri Lanka) the MSW generation is 2,927 ton/day[1]. The composition of the waste, in general, differs from country to country on the economic level of countries as well as other factors such as geographical location, energy resources,

* Corresponding author:

pravinsingare@gmail.com (Pravin U. Singare) Published online at http://journal.sapub.org/ms

Copyright $(2012$ Scientific \& Academic Publishing. All Rights Reserved climate, living standards and cultural habits. Most of the developing Asian countries have high percentage (50 to $80 \%$ ) of organic matter in their waste stream with high moisture content making them unsuitable for incineration[1]. The indiscriminate disposal of solid waste in most of the cities has resulted in rapid environmental degradation thereby creating threat to public health. The environmental degradation caused by inadequate disposal of solid waste can be expressed by the contamination of surface and ground water through leachate, soil contamination through direct waste contact or leachate, air pollution by burning of wastes, spreading of diseases by different vectors like birds, insects and rodents, or uncontrolled release of methane by anaerobic decomposition of waste.

The rapid process of urbanization and subsequent increase in solid waste generation has also changed the traits of disaster risk and cities have now become 'crucibles of risk' [8]. Increased solid waste generation creates more environmental problems, as many cities often faces natural disasters like flood. According to a report of the World Bank, about 3.4 billion people, i.e., more than half of the world's population lives in areas where at least one disaster could significantly impact those[9]. Recent incidents have highlighted the vulnerability of cities, in particular, to climatic disasters and different environmental shocks. In July 2005, Mumbai, India, was struck by a cyclone that dumped $94 \mathrm{~cm}$ of rain in less than 24 hours, leaving more than 1000 people dead, mostly in slum settlements. Despite the heavy rainfall followed by 
flood in Mumbai on July, 2005, not much quantification studies on the accumulation of solid waste material have been made[10-13]. It is estimated that Mumbai alone generates about 365 million tones of sewage annually[14]. Most of the sewage is carried through drainage and reaches the sea at various points or dumped indiscriminately into the sea. One such classical example is the Mahim creek of Mumbai which is the biggest sink for most of the waste generated by residential and industrial complexes. It is a less known fact that the Mahim bay area, where Mahim creek meets Arabian Sea, is a nominated bird sanctuary called "Salim Ali Bird Sanctuary" where migratory birds come for nesting. The mangrove along the creek area plays an important role in the survival of many coastal communities and harbors a unique biodiversity[15]. The mangrove forests are important for various reasons. Their role in harboring a variety of biotic communities, protecting the coastal areas from cyclonic storms and functioning as lungs in the case of Mumbai, is of considerable importance from the conservation point of view. This mangrove grown along the Mahim creek represents a fragile ecosystem which requires considerations from pollution point of view, so that it is not destroyed. For conservation of these mangroves, it is necessary to have a wellplanned waste management system, which further requires quantification and characterization of generated solid waste. Understanding the existing status, an attempt has been made in the present study to quantify the accumulation of three important types of NBDSW material in the mangroves of Mahim creek at Mumbai.

\section{Materials and Method}

\subsection{Study area}

Mahim Creek (locally known as Bandra ki Khadi) is a creek in Mumbai, India. The Mithi River drains into the creek which drains into the Mahim Bay. The creek forms the boundary between the city and suburbs. The creek is swamped by mangroves (Figure 1) and has a mini-ecosystem within it. The depth of the creek is 15 feet $(4.6 \mathrm{~m})$. It is the only Creek which balances the water level of Mumbai during heavy rainfall and during Mumbai monsoon time. The waters of the creek are foul smelling due to the dumping of untreated industrial effluents further upstream. In recent years, the mushrooming of slums around the Mahim creek (Figure 2) has caused concern for the mangrove ecosystem, vital to the ecosystem of Mumbai.

\subsection{Climate}

The area is located along western Arabian cost of India from $19^{\circ} 2^{\prime} 52.84$ ' "north and from $72^{\circ} 50^{\prime} 17.56^{\prime}$ " east. The area experiences tropical savanna climate. It receives heavy south west monsoon rainfall, measuring $2166 \mathrm{~mm}$ on an average every year. The temperature ranges from $16{ }^{\circ} \mathrm{C}$ to $39{ }^{0} \mathrm{C}$ with marginal changes between summer and winter months. Whereas relative humidity ranges between 54.5 to
$85.5 \%$.

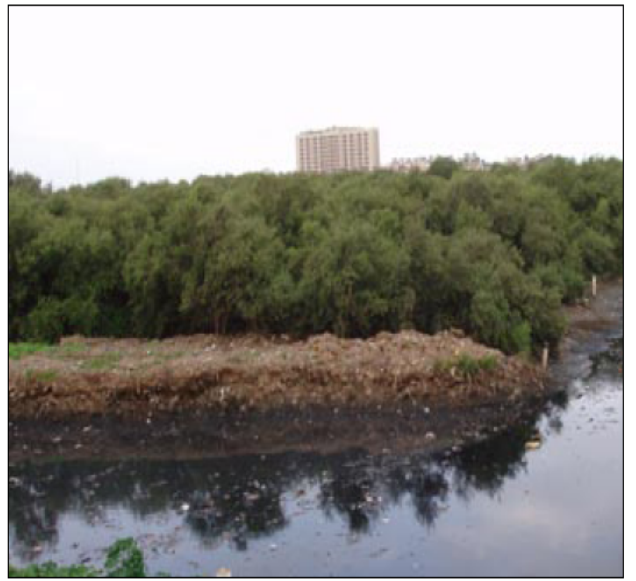

04 Mangrove at Mahim creek

Figure 1. NBDSW Accumulation in the Mangroves grown along the Mahim Creek of Mumbai.

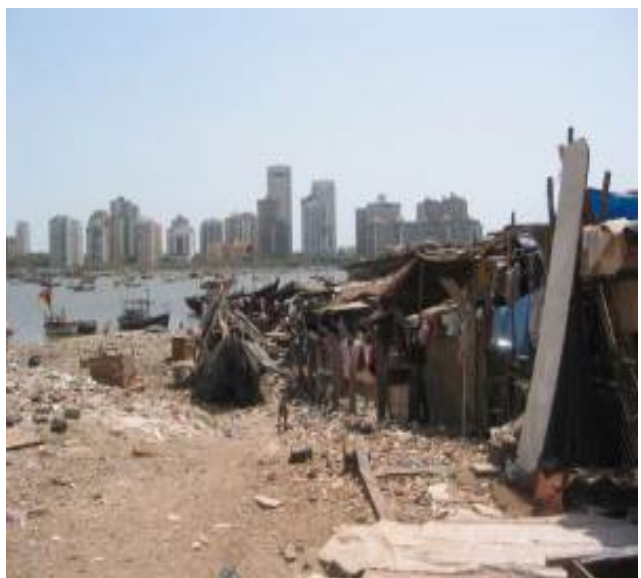

Figure 2. A slum on the banks of Mahim Creek, with highrises in the distance.

\subsection{Methodology}

The solid waste accumulated along the study area was separately cleared before spring tide. The predominant solid wastes, viz. plastics, glass and synthetic rubber were collected, washed and weighed after drying. The quantification studies were repeated after the spring tide to know their accumulation in one spring tide ( 15 days). The results are presented in kilograms per hectare. The present study was carried out to quantify the accumulated NBDSW materials from October 2010 to February 2011. The solid waste material was properly dumped in the garbage depots after the quantification studies were finished.

\section{Results and Discussion}

The present study shows accumulation of enormous quantity of NBDSW materials along the Mahim creek of Mumbai. These materials enter the creek through different point sources. It is observed that the slums along the Mahim creek are the major sources of pollution. The domestic 
sewage channels often bring a lot of solid waste in the form of plastic bottles; carry bags, thermocol, footwear and rubber tubes, etc into the creek.

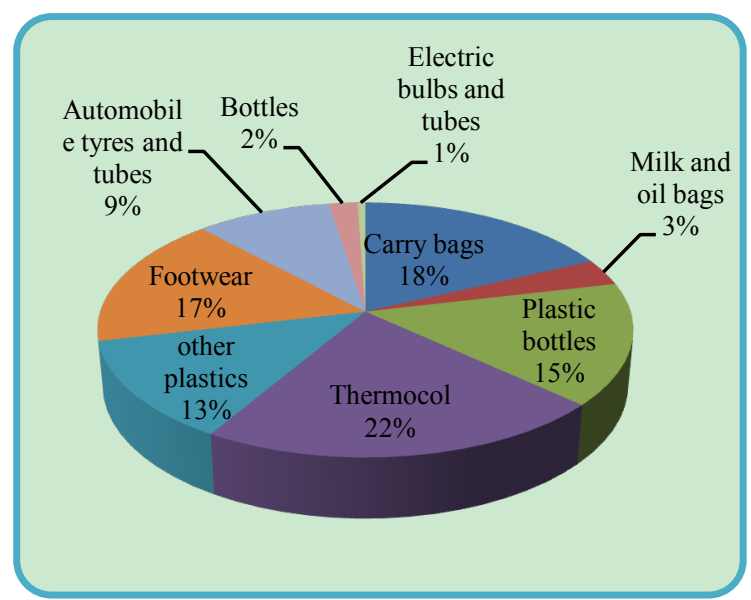

Figure 3. NBDSW materials collected along Mahim creek during first sampling.

In the present investigation it was observed that in terms of dry weight, plastic materials were at the top contributing $71 \%$ and 55\% during first and second sampling respectively. Among the plastic materials collected, thermocol (polystyrene), carry bags and plastic bottles were most abundant (Table 1). It was observed that thermocol was the most prominent plastic NBDSW material contributing to $22 \%$ and $19 \%$, followed by carry bags contributing to $18 \%$ and $13 \%$ and plastic bottles contributing $15 \%$ and $10 \%$ in first and second sampling respectively (Figures 3 and 4). Considering the meager weight of thermocol, the number of thermocol, which have constituted $65.48 \mathrm{~kg}$ and $14.34 \mathrm{~kg}$ of dry weight (during first and second sampling respectively), was enormous (Table 1). In fact, all these plastic NBDSW materials cover most of the mud flats areas thereby narrowing the flow of Mahim creek.

Table 1. Accumulation of NBDSW material along Mahim Creek of Mumbai.

\begin{tabular}{|c|c|c|c|}
\hline \multicolumn{2}{|c|}{ NBDSW } & \multirow{2}{*}{ Time } & \multirow{2}{*}{$\begin{array}{l}\text { Accumulation dry } \\
\text { wt in (kg/hectar) }\end{array}$} \\
\hline Category & Sub-Category & & \\
\hline \multirow{10}{*}{ Plastics } & \multirow{2}{*}{ Carry bags } & Initial Collection & 54.19 \\
\hline & & After Spring Tide & 10.11 \\
\hline & \multirow{2}{*}{$\begin{array}{l}\text { Milk and oil } \\
\text { bags }\end{array}$} & Initial Collection & 10.12 \\
\hline & & After Spring Tide & 1.39 \\
\hline & \multirow{2}{*}{ Plastic bottles } & Initial Collection & 46.73 \\
\hline & & After Spring Tide & 7.99 \\
\hline & \multirow{2}{*}{$\begin{array}{c}\text { Thermocol } \\
\text { (polystyrene) }\end{array}$} & Initial Collection & 65.48 \\
\hline & & After Spring Tide & 14.34 \\
\hline & \multirow{2}{*}{ Other plastics } & Initial Collection & 38.61 \\
\hline & & After Spring Tide & 8.38 \\
\hline \multirow{4}{*}{ Rubber } & \multirow{2}{*}{ Footwear } & Initial Collection & 50.47 \\
\hline & & After Spring Tide & 18.88 \\
\hline & \multirow{2}{*}{$\begin{array}{c}\text { Automobile } \\
\text { tyres and tubes }\end{array}$} & Initial Collection & 28.39 \\
\hline & & After Spring Tide & 12.17 \\
\hline \multirow{4}{*}{ Glass } & \multirow{2}{*}{ Bottles } & Initial Collection & 5.96 \\
\hline & & After Spring Tide & 2.43 \\
\hline & \multirow{2}{*}{$\begin{array}{c}\text { Electric bulbs } \\
\text { and tubes }\end{array}$} & Initial Collection & 1.65 \\
\hline & & After Spring Tide & 0.46 \\
\hline
\end{tabular}

After plastics, synthetic rubber was the second largest NBDSW material contributing to $26 \%$ and $41 \%$ during first and second sampling respectively. Among the synthetic rubber, footwear contribute to $17 \%$ and $25 \%$, while automobile tyres and rubber tubes contribute to $9 \%$ and $16 \%$ during initial and final sampling respectively (Figures 3 and 4). Accumulation of glass NBDSW material was found to be $3 \%$ and $4 \%$ in the respective collections (Figures 3 and 4 ). Tidal as well as wind action carry most of the solid waste which gets accumulated in the river. In last many years, there has been extensive encroachment by hutments along the Mahim creek area. Some of the plastic carry bags and thermocol (polystyrene) from these hutments also find their way into the creek.

The overall results indicate that there is a greater accumulation of plastic and rubber NBDSW materials along the Mahim creek of Mumbai which not only destroy the aesthetic beauty of the creek but also widens and strengthens the mudflats, resulting in the narrowing of the creek (Figure 1). Also continuous accumulation of NBDSW materials in the mangroves can change the physico-chemical environment of the sediments by restricting the entry of sunlight and air thereby affecting the nutrient recycling process of the entire mangrove ecosystem.

Recommendations: Considering the tremendous discharge of NBDSW materials in Mahim Creek of Mumbai, it is of great importance to process and finally dispose of the accumulated solid waste in a safe manner. Among the different NBDSW materials collected along the Creek, plastics and synthetic rubber accumulation can be controlled by recycling and incineration, while glass can only be recycled.

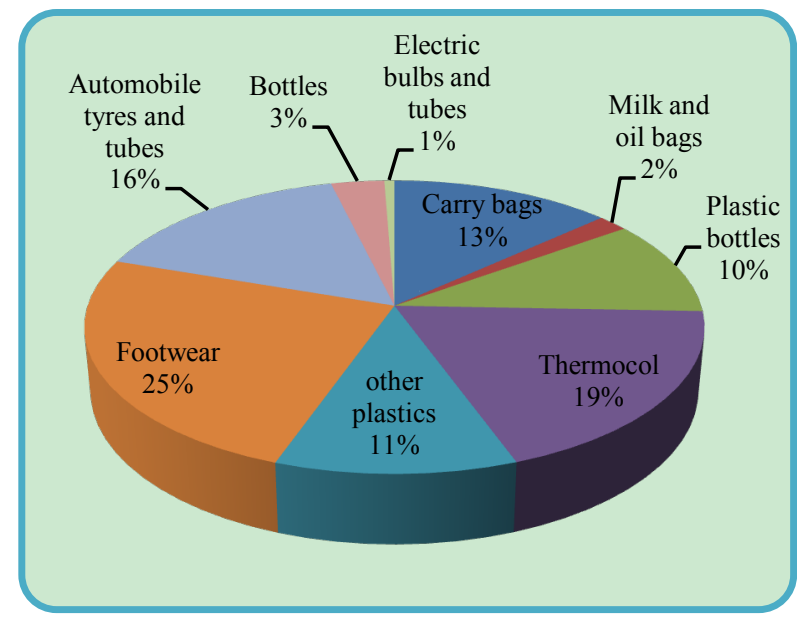

Figure 4. NBDSW materials collected along Mahim creek during second sampling.

The adoption and transfer of the NBDSW management technologies from the developed countries without adapting them to the local or regional perspective would be fallacious on the part of the developing countries like India. Therefore, the technical aspects for a sustainable NBDSW management would have to take into account the following points for planning and implementation of strategies.

(1) Provision of facilities for primary collection of waste 
from curbside/community bins and adequate storage facilities in the urban areas based on the population density.

(2) Transportation of waste from the community storage facilities at regular intervals and improvement in the waste collection fleet.

(3) Transfer stations (at optimal distances from residential areas) should be constructed wherever necessary with provision for weighbridges.

(4) There must be a separate system for hospitals, health care establishments and industries to prevent the infectious and hazardous non-biodegradable solid wastes from entering the municipal waste stream.

Sustainable NBDSW management would also call for the strengthening of the management sector which has to go hand in hand with the above technical planning. An executable master plan and implementation plans for NBDSW management at the provincial level or the state level in accordance with the strategy for national environmental quality would help the management. The application of polluter pays principle to all waste generators, especially in urban areas including governmental and non-governmental agencies, private sectors and commercial enterprises; application of the 3R (Reduce-Recycle-Reuse) concepts, product stewardship, cleaner production and specification in the selection of packaging materials to the manufacturers is highly recommended. In addition to these there should be continuous monitoring and record keeping of non-biodegradable solid waste aspects with the development of a systematic information system that can be comparable, utilizable and updated; appointment of responsible governmental agencies that can regulate and supervise non-biodegradable solid waste management activities of both local government and private operators so as to reduce the environmental impacts. It is also important to provide organizational support by encouraging the involvement of private sector operators, NGOs and Community Based Organizations (CBOs); and finally the informal sector needs to be formalized.

\section{Conclusions}

The Mahim creek of Mumbai is one of the most polluted creeks of India. Non-biodegradable solid waste pollution is the only type of pollution that has been highlighted in the present paper. The life in the creek suffers from a variety of stresses. The animal life of the creek is reported to accumulate high levels of heavy metal pollution. Added to this, indiscriminate felling of trees for fuel during low tide and ill planned exploitation of existing fish and crab resources might endanger the wildlife and might cause irreversible damage to the ecosystem. No doubt the study reveals that the existing infrastructure to clean or protect the creek is insufficient. Most of the NBDSW can be cleared from the point sources if the corporations surrounding the creek develop proper organizational skills and infrastructure. This would cost less than clearing the creek. The natural advantage with NBDSW materials studied in the area is that most of them can be recycled.

The effects of NBDSW accumulation on the mangrove ecosystem as observed during the study have been summarized below.

NBDSW accumulated in the mangrove can change the physico-chemical environment of the sediments by restricting the entry of sunlight and air. This can affect the nutrient recycling process of the entire mangrove ecosystem.

Solid wastes spread on the mangrove area prevent the development of seedlings from propagules.

Solid waste accumulation can affect the benthic fauna, the most important component of detritus food chain in the mangrove swamps.

Accumulation of solid waste destroys the aesthetic beauty of the beaches and seashores. The continuous process of accumulation of these materials widens and strengthens the mudflats, which results in the narrowing of the channels.

Due to their varied sizes and colours, plastics and thermocol are wrongly taken as food by fishes, birds and crabs. This can prove to be fatal to these organisms. Such examples are frequently observed and also documented in urban environment. It can pose severe threats to the existing mangrove plants and will affect the regeneration process of the mangrove ecosystem.

Since the collection and removal of solid wastes from mangrove areas is practically impossible, the only alternative is to prevent the NBDSW from entering the creek. This process should be immediately started through awareness programs and educating the people from various walks of life. Relocating the solid waste dumping yards away from the creek will also help solve the problem to a greater extent. For this, a clear-cut planning is required from the government agencies functioning at various levels to regulate the disposal of NBDSW material, before it is too late.

\section{ACKNOWLEDGEMENTS}

The authors are extremely thankful to SAP Productions for developing and maintaining the manuscript template.

\section{REFERENCES}

[1] Asian Institute of Technology - AIT, 2004, Municipal Solid Waste Management in Asia., Asian Regional Research Program on Environmental Technology (ARRPET), AIT, Thailand. ISBN: 974-417-258-1

[2] United Nations Environmental Program (UNEP), 2001, State of Environment Bhutan., UNEP, ISBN: 92-807-2012-5

[3] Iftekhar, E., Sinha, A.H.Md., and Khan, S.S.A.,2005, A report on 'Urban Solid Waste Management Scenario of Bangladesh:Problems and Prospects', Waste Concern Publications, Dhaka, Bangladesh Available online:

http://www.wasteconcern.org/_as of August 2006

[4] UNEP (United Nations Environment Program),2003, fgha- 
nistan - Post Conflict Environmental Assessment., UNEP, ISBN 92-1-158617-8

[5] United Nations Environmental Program (UNEP), 2001, State of Environment South Asia., UNEP, ISBN: 92-807-2137-2

[6] WWF (World Wildlife Fund) -Pakistan, 2001, Pakistan country report Waste Not Asia conference 2001, Taipei, Taiwan. Available online

http://www.noburn.org/regional/pdf/country.pdf as of August 2006

[7] Manandhar, R., 2002, Private Sector Participation in SolidWaste Management in Kathmandu., Kitakyushu Initiative Seminar on Solid Waste Management, 19-20 September 2002, Kitakyushu, Japan

[8] Pelling, M., 2003, The Vulnerability of Cities: Natural Disa ters and Social Resilience., London: Earthscan

[9] Dilley, M., Robert, S. C., Uwe, D., Lam, A.L.L. and Margaret, A., 2005, Natural Disaster Hotspots: A Global Risk Analysis. Washington DC: World Bank. Available online http://www.Ideo.columbia.edu/chrr/research/hotspots/coreda ta.html)
[10] Singare, P. U., 2011, Study of some Major Non- Biodegradable Solid Wastes along Thane Creek of Mumbai., World Environment. (In Press)

[11] Singare, P. U., 2012, Study on Accumulation of Non- Biodegradable Solid Wastes along Ulhas River of Thane, Mumbai, Interdisciplinary Environmental Review. (In Press)

[12] Singare, P. U., 2012, Environmental Assesment of Some Non-Biodegradable Solid Wastes Along Vasai Creek of Mumbai, Interdisciplinary Environmental Review (In Press)

[13] Shindikar, M., Jadhav, S., Karpe, R., Gunale, V.R., Lale, M., and P. Tetali, Quantification Studies on the Accumulation of Non-Biodegradable Solid Waste Material in the Mangroves of Thane Creek, in Proc. of Lake 2000, International Symposium on Restoration of Lakes and Wetlands, Section-4 (Indian Institute of Science, Bangalore, India, 2000) Paper-1

[14] Glasby G.P., and Roonwal G.S., 1995, Marine pollution in India: an emerging problem. Curr. Sci. 68(1), pp.495-497

[15] Untawale, A.G., 1986, India, Country Report: Asia. pp.51-87. In: Mangroves of Asia and the Pacific: Status and Management Technical Report of the UNDP/UNESCO, Research and Training Pilot Programme on Mangrove ecosystems in Asia and the Pacific, Quezon City, Manila 